\title{
Supplementary Informaton for
}

Quantification of nitrous acid (HONO) and nitrogen dioxide (NO2) in ambient air by broadband cavity-enhanced absorption spectroscopy (IBBCEAS) between 361 - $388 \mathrm{~nm}$

5 Nick Jordan ${ }^{1}$ and Hans D. Osthoff ${ }^{1}$

${ }^{1}$ Department of Chemistry, University of Calgary, 2500 University Drive NW, Calgary, AB T2N

1N4, Canada

Correspondence to: Hans D. Osthoff (hosthoff@ucalgary.ca) 


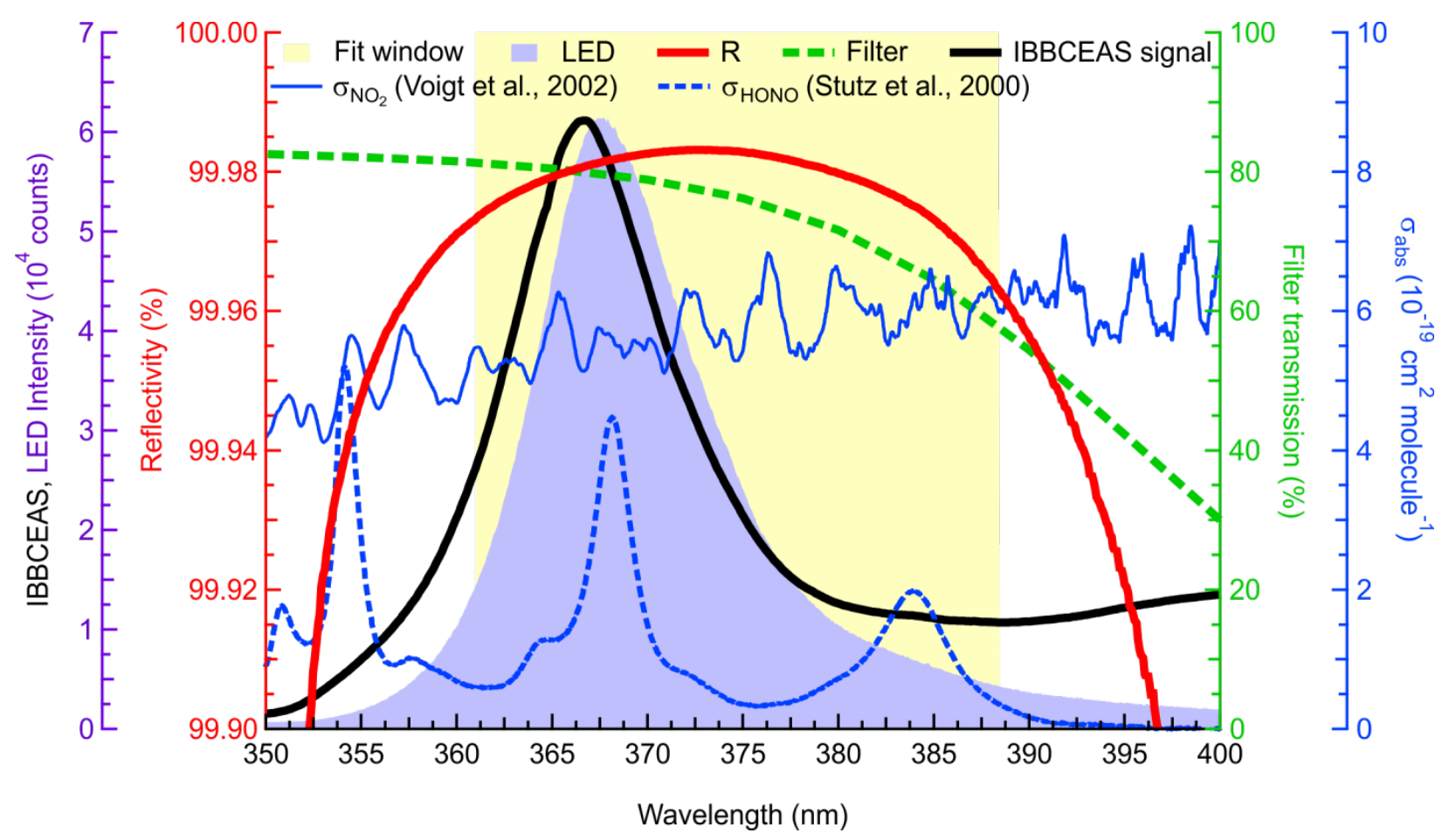

Figure S1 Absorption spectroscopy in the 350-400 nm spectral window. The LED output (blue area) was measured by directing the LED output through the cavity sample cell in the absence of the broadband mirrors and peaked at $367.8 \mathrm{~nm}$. A bandpass filter (green dashed line) was used to cut out stray light and unwanted emission from the LED outside the maximum mirror reflectivity range (i.e., > $390 \mathrm{~nm}$ ). The mirror reflectivity (see section 2.2 of the main manuscript) is shown in red. The cavity output spectrum (black) is a convolution between the LED output, the mirror curve and the bandpass filter function; its intensity is scaled to that of the LED output for presentation purposes. The absorption cross-sections of HONO (blue dashed line) and $\mathrm{NO}_{2}$ (solid blue line) are superimposed. The yellow shaded region shows the spectral fit window used in the data retrieval. 


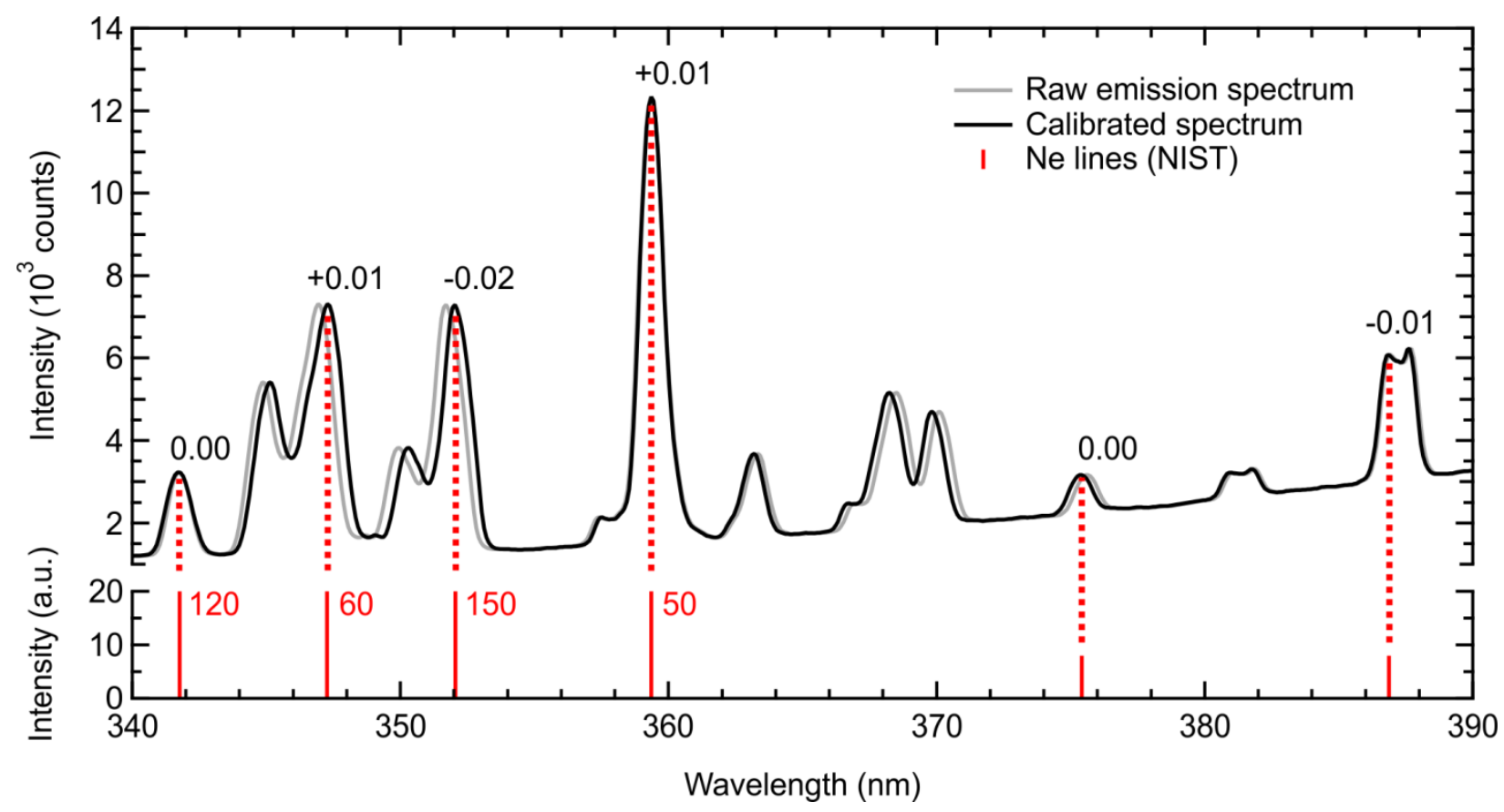

Figure S2 An illustration of the Ne calibration lamp emission spectrum between 340 and $390 \mathrm{~nm}$. The grey trace shows the raw spectrum recorded by the spectrograph while the black trace is that of the calibrated spectrum using a $5^{\text {th }}$ degree polynomial fit to the raw lines in Table S1. The relative intensities of the Ne spectral lines are indicated on the graph (in red), as well as the relative difference (+/-) between 25 the raw and calibrated spectrum (in black). Dotted red lines are used as a visual guide.

Table S1 Ne lamp spectral line intensities at the raw, calibrated and literature (Bartmess, 2011) wavelengths.

\begin{tabular}{cccc}
\hline $\begin{array}{c}\text { Raw line } \\
(\mathbf{n m})\end{array}$ & $\begin{array}{c}\text { Calibrated line } \\
(\mathbf{n m})\end{array}$ & $\begin{array}{c}\text { Ne lamp emission line } \\
(\mathbf{n m})\end{array}$ & $\begin{array}{c}\text { Difference } \\
(+/-\mathbf{n m})\end{array}$ \\
\hline 341.80 & 341.79 & 341.79 & 0.00 \\
346.93 & 347.27 & 347.26 & +0.01 \\
351.70 & 352.03 & 352.05 & -0.02 \\
359.34 & 359.36 & 359.35 & +0.01 \\
375.65 & 375.42 & 375.42 & 0.00 \\
386.94 & 386.87 & 386.88 & -0.01 \\
\hline
\end{tabular}




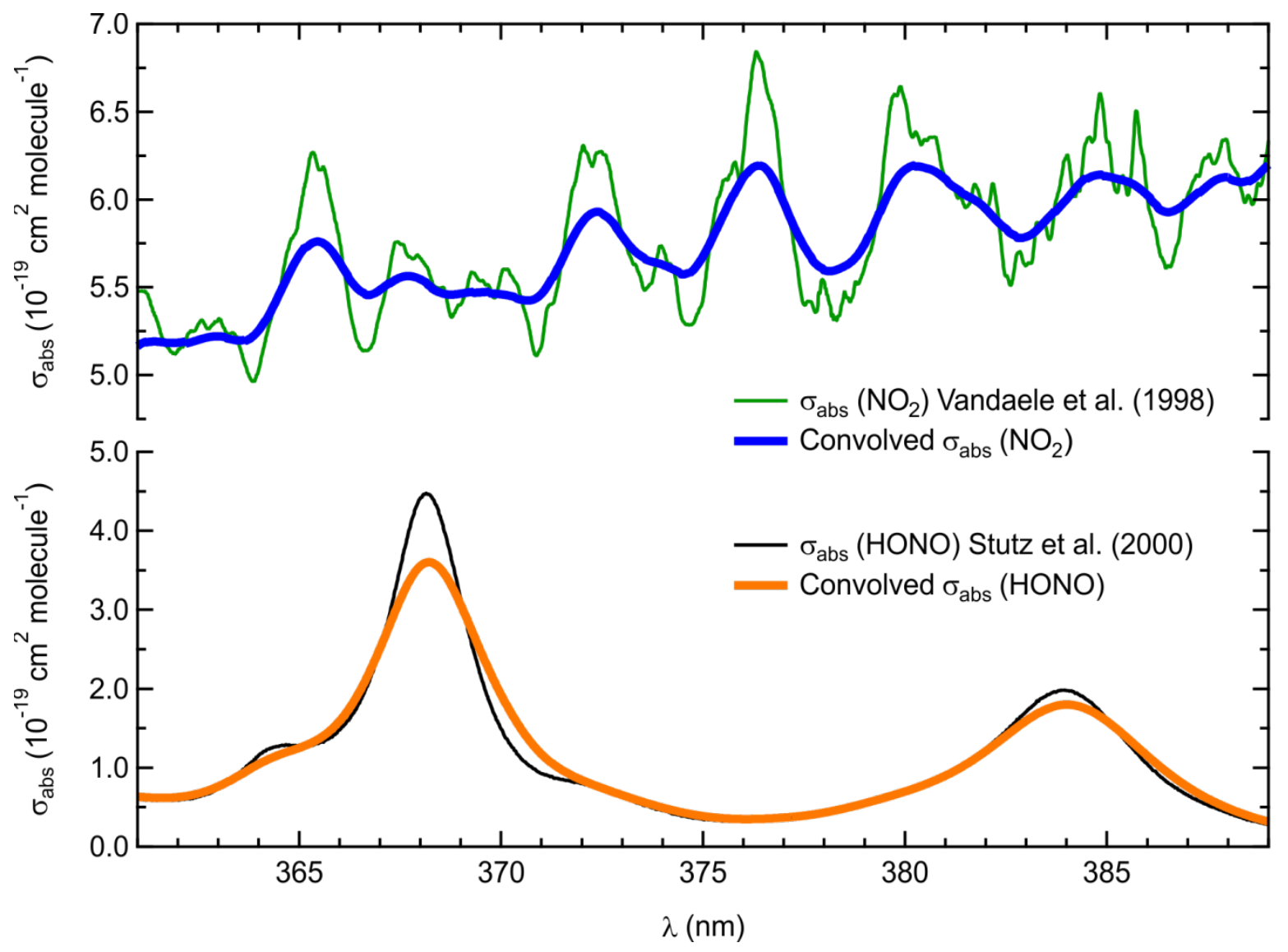

Figure S3 Literature and convolved absorption cross-sections of $\mathrm{NO}_{2}$ and HONO. The absorption crosssection of $\mathrm{NO}_{2}$ is from Vandaele et al. (1998). The absorption cross-section of HONO is that by Stutz et 35 al. (2000). 

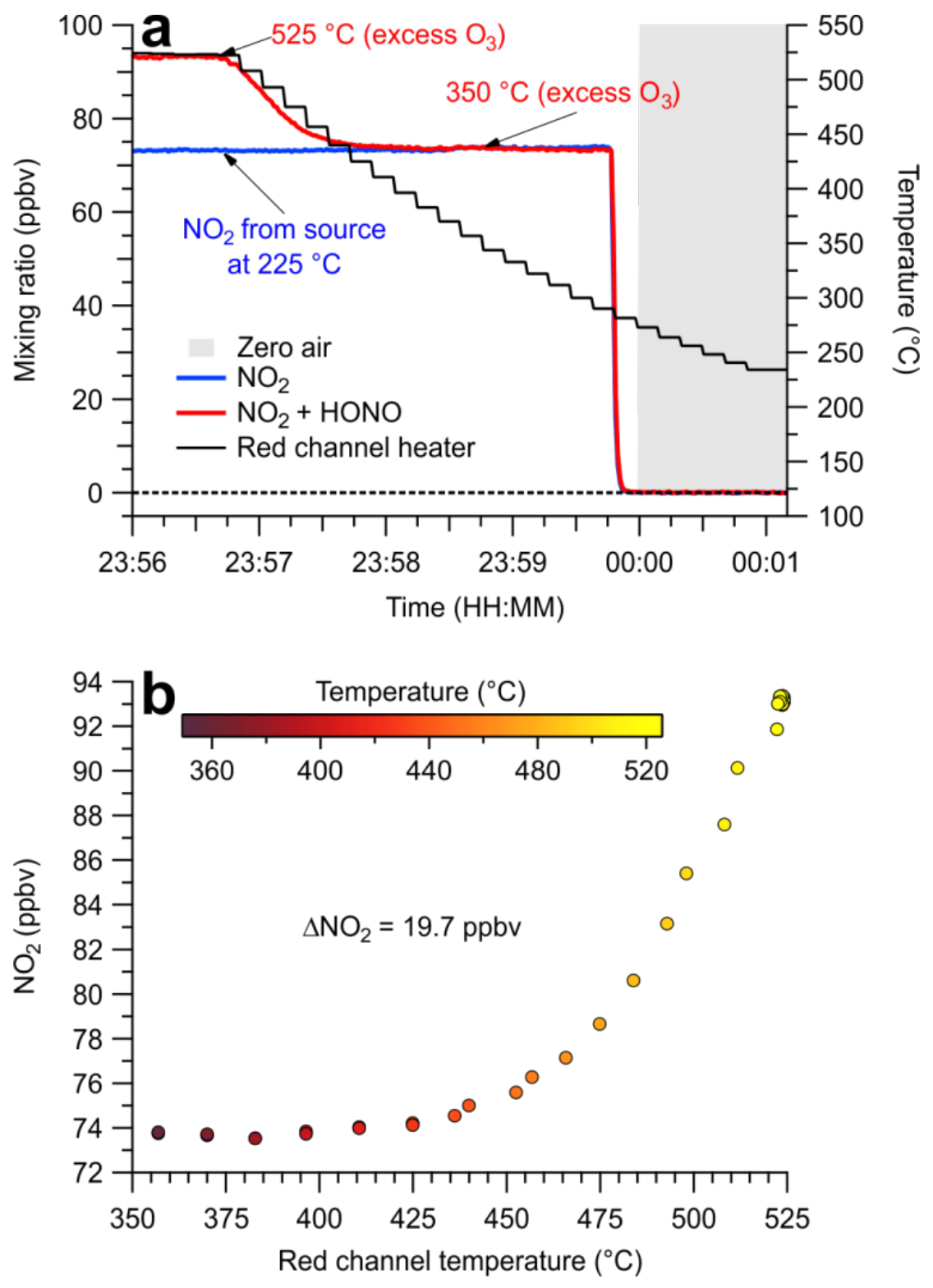

Figure S4 Measurement of HONO mixing ratios by TD-CRDS. a) Sample inlet temperature scan. The heated red ("hot") channel detects $\mathrm{NO}+\mathrm{O}_{3}$, i.e. $\mathrm{NO}_{2}$ on top of a $\mathrm{NO}_{\mathrm{x}}$ background, while the blue channel 40 measures $\mathrm{NO}_{2}$ at a reference temperature. The black trace shows the quartz inlet temperature, which was decremented by $10{ }^{\circ} \mathrm{C}$ every $10 \mathrm{~s}$. b) Mixing ratio observed in the $\mathrm{NO}_{2}+\mathrm{HONO}$ channel as a function of inlet temperature. The contribution from $\mathrm{HONO}\left(\Delta \mathrm{NO}_{2}\right)$ is measured from the flat ("cold") portion of the curve to the vertex ("hot”) end of the ramp. 

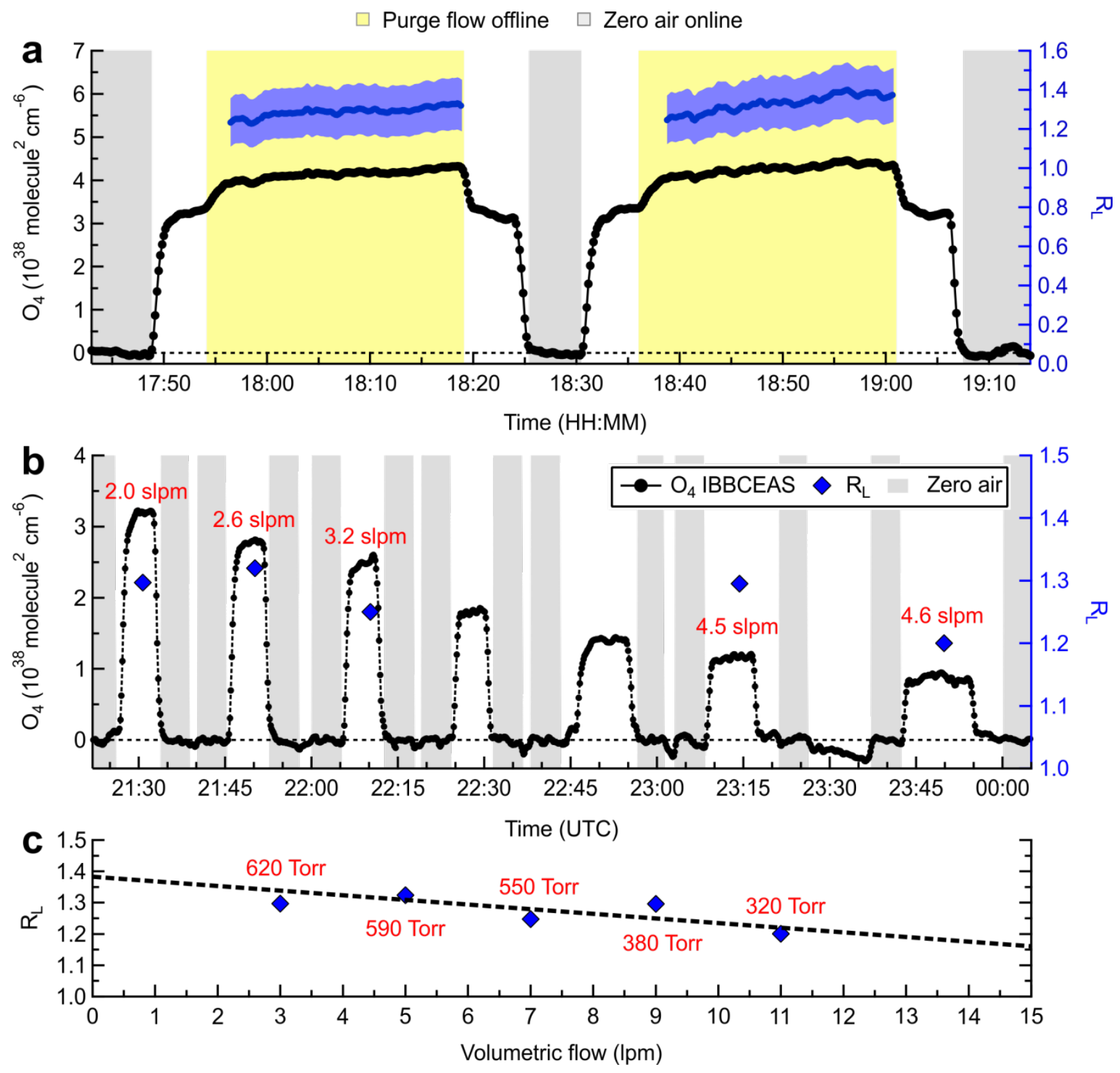

45 Figure S5 Determination of the cavity effective absorption path length: a) as $R_{L}$ using $\mathrm{O}_{4}$ from the ratio of the $\left[\mathrm{O}_{2}\right]_{\text {on }}$ and $\left[\mathrm{O}_{2}\right]_{\text {off }}$ using Eq. (4). Both sets were carried out at ambient pressure ( $\left.880 \mathrm{hPa}\right)$. Blue shaded areas give $R_{L} \pm 2 \sigma ; \mathbf{b}$ ) in a varied sample flow rate. At a higher volumetric flow rate (c), $d_{0}$ converges to $d$ due to diffusion of the sample gas into the purge volumes of the instrument. 

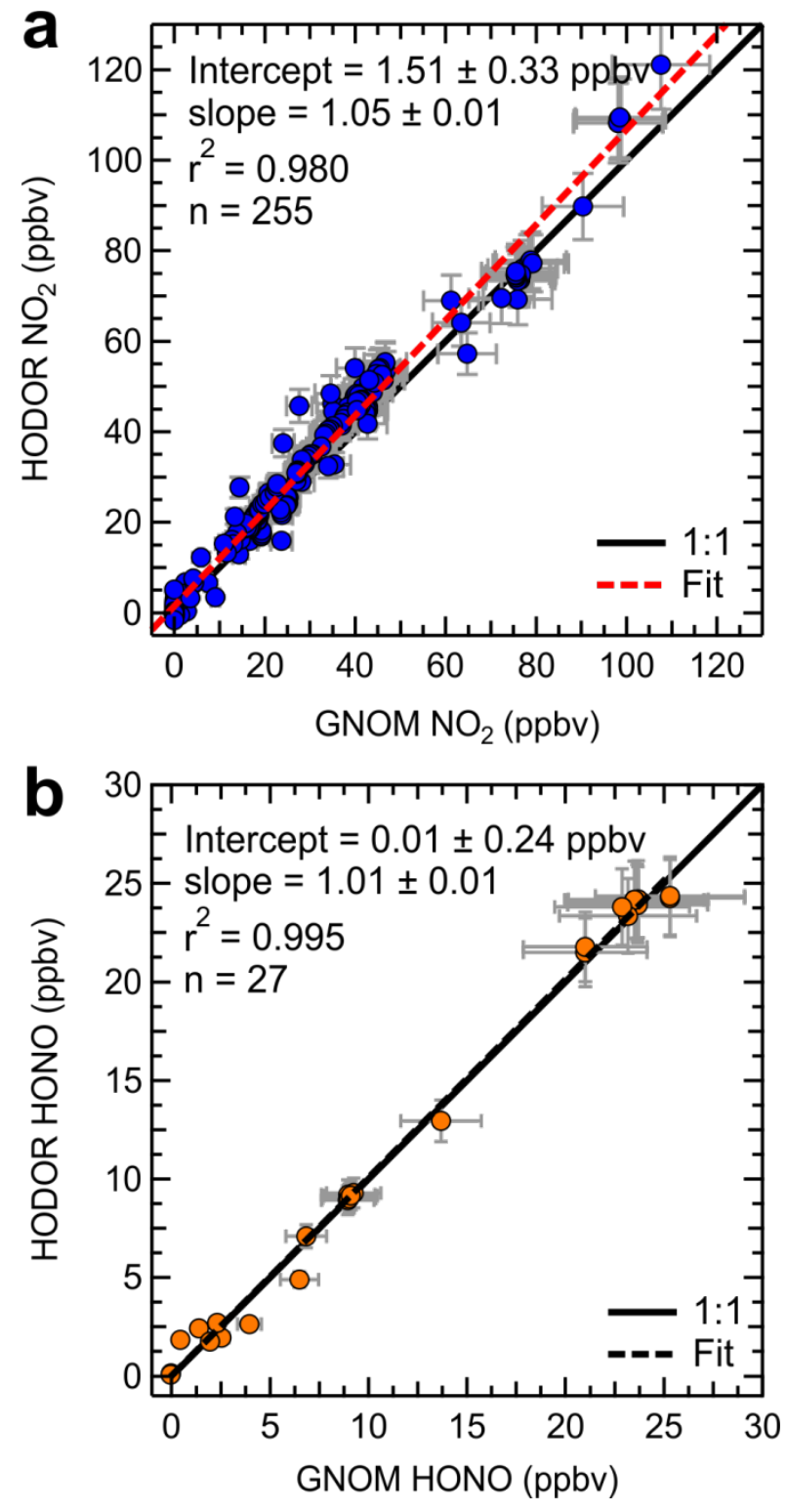

Figure S6 Scatter plots for: a) $\mathrm{NO}_{2}$ and b) $\mathrm{HONO}$. Error bars give the $\pm 1 \sigma$ uncertainty in each measurement method. 


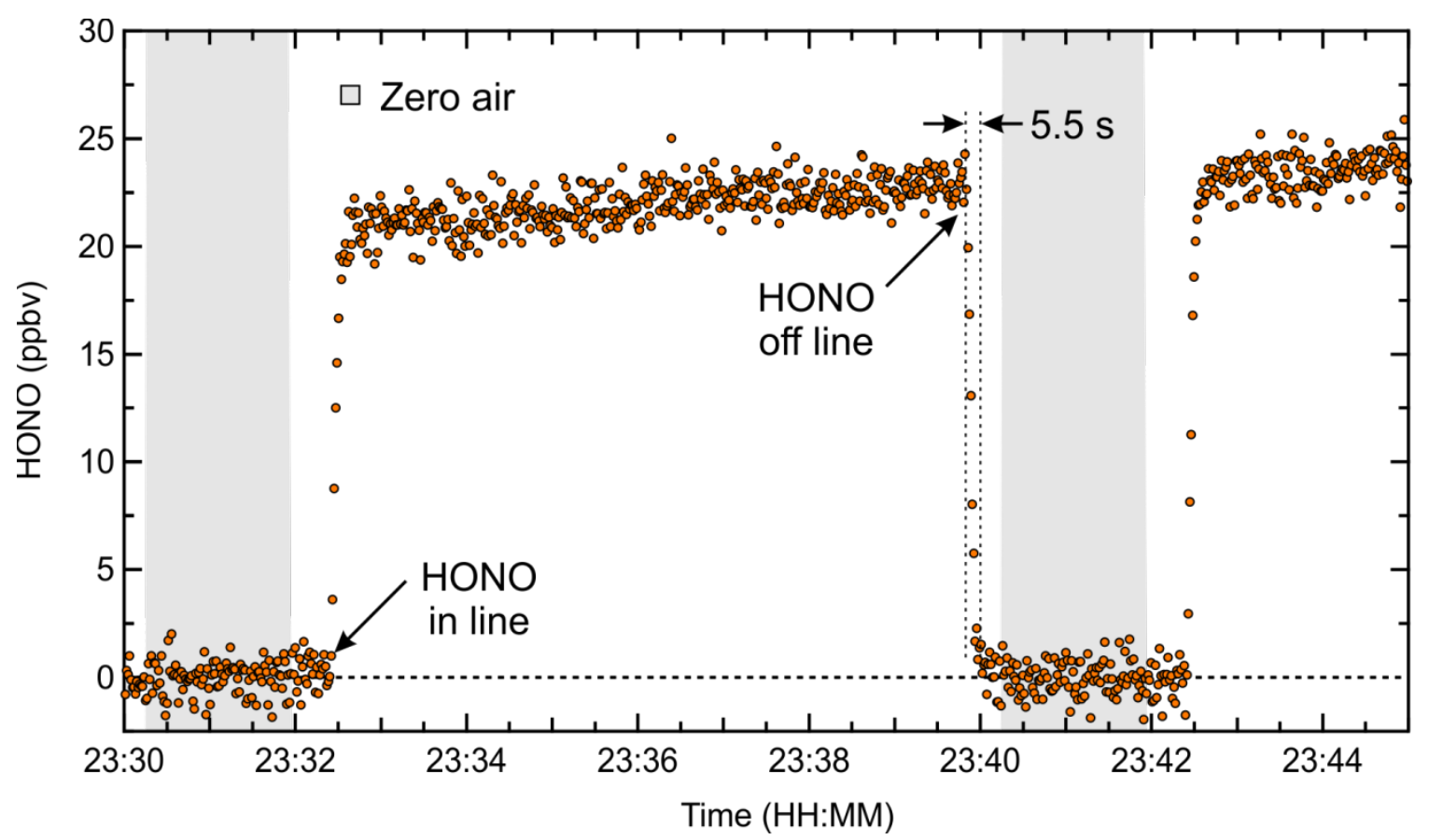

Figure S7 Time series of IBBCEAS HONO data at $1 \mathrm{~s}$ time resolution. The grey shaded regions represent the zero air intervals used in the data reduction. The onset and end of the actual zero intervals coincides with the sharp changes in the mixing ratio of either absorber. The rise ( $0 \%$ to $100 \%)$ time between sample 60 and zero is $\sim 5.5 \mathrm{~s}$, consistent with the sample flow rate of $2 \mathrm{slpm}$ for which the sample residence time is $5.5 \mathrm{~s}$. 


\section{References}

65

Bartmess, J. E.: NIST Chemistry WebBook, NIST Standard Reference Database Number 69, in, edited by: Linstrom, P. J., and Mallard, W. G., National Institute of Standards and Technology, Gaithersburg MD http://webbook.nist.gov (retrieved June 16, 2011). 2011.

Stutz, J., Kim, E. S., Platt, U., Bruno, P., Perrino, C., and Febo, A.: UV-visible absorption cross sections of nitrous 70 acid, J. Geophys. Res., 105, 14585-14592, 10.1029/2000JD900003, 2000.

Vandaele, A. C., Hermans, C., Simon, P. C., Carleer, M., Colin, R., Fally, S., Merienne, M. F., Jenouvrier, A., and Coquart, B.: Measurements of the $\mathrm{NO}_{2}$ absorption cross-section from $42000 \mathrm{~cm}^{-1}$ to $10000 \mathrm{~cm}^{-1}(238-1000 \mathrm{~nm})$ at $220 \mathrm{~K}$ and $294 \mathrm{~K}$, Journal of Quantitative Spectroscopy \& Radiative Transfer, 59, 171-184, 10.1016/s00224073(97)00168-4, 1998.

75 